\title{
BMJ Open Sleep problems of healthcare workers in tertiary hospital and influencing factors identified through a multilevel analysis: a cross-sectional study in China
}

\author{
Huan Liu (D) , ${ }^{1}$ Jingjing Liu, ${ }^{1}$ Mingxi Chen, ${ }^{1}$ Xiao Tan, ${ }^{1}$ Tong Zheng, ${ }^{1}$ Zheng Kang, ${ }^{1}$ \\ Lijun Gao, ${ }^{1}$ Mingli Jiao (D) , ${ }^{2}$ Ning Ning, ${ }^{1}$ Libo Liang, ${ }^{1}$ Qunhong Wu, ${ }^{1}$ Yanhua Hao ${ }^{1}$
}

To cite: Liu H, Liu J, Chen M, et al. Sleep problems of healthcare workers in tertiary hospital and influencing factors identified through a multilevel analysis: a cross-sectional study in China. BMJ Open 2019;9:e032239. doi:10.1136/ bmjopen-2019-032239

- Prepublication history and additional material for this paper are available online. To view these files, please visit the journal online (http://dx.doi. org/10.1136/bmjopen-2019032239).

Received 09 June 2019 Revised 02 December 2019 Accepted 05 December 2019

Check for updates

(C) Author(s) (or their employer(s)) 2019. Re-use permitted under CC BY-NC. No commercial re-use. See rights and permissions. Published by BMJ.

${ }^{1}$ Department of Social Medicine, Health Management College, Harbin Medical University, Harbin, China

${ }^{2}$ Department of Health Policy, Health Management College, Harbin Medical University, Harbin, China

Correspondence to Professor Qunhong Wu; wuqunhong@163.com

Professor Yanhua Hao; hyhyjw@126.com

\section{ABSTRACT}

Objectives Sleep problems are common among healthcare workers, especially among those who work in tertiary hospitals; however, studies focusing on healthcare workers in tertiary hospitals in China are limited. Therefore, we aimed to examine the prevalence of sleep problems among tertiary hospital employees in China and identify associated factors.

Design Cross-sectional questionnaire survey study.

Setting The study was conducted in 317 departments at 33 tertiary hospitals in the Heilongjiang Province, China.

Participants The study included a representative sample of 4007 healthcare workers, including clinicians, medical technicians and office workers, who were selected using a multistage cluster sampling method. Ultimately, 3810 participants completed valid questionnaires, yielding a response rate of $95 \%$.

Primary and secondary outcome measures Participants completed a structured questionnaire which collected data regarding demographics, sleep problems, employment, chronic pain and health-related behaviours. A two-level logistic regression model was constructed to examine determinants of sleep problems.

Results We found that nearly half of the respondents reported experiencing sleep problems. The two-level logistic model suggested a positive association of sleep problems with headache $(\mathrm{OR}=2.64,95 \% \mathrm{Cl}=2.27$ to 3.07), working hours ( $0 \mathrm{R}=1.41,95 \% \mathrm{Cl}=1.20$ to 1.66$)$ and night shifts $(\mathrm{OR}=1.43,95 \% \mathrm{Cl}=1.21$ to 1.69$)$. In contrast, regular diet $(\mathrm{OR}=0.44,95 \% \mathrm{Cl}=0.36$ to 0.53$)$ and exercise $(\mathrm{OR}=0.65,95 \% \mathrm{Cl}=0.53$ to 0.80$)$ protected the study population against sleep problems.

Conclusions We found that sleep problems are prominent among tertiary hospital employees in China. The risk factor most strongly associated with sleep problems was headaches. To alleviate sleep problems in this population, medical institutions and health policy makers should establish reasonable working schedules and night-shift work systems, while the healthcare workers themselves should pay attention to their chronic pain problems and engage in regular diet and exercise.

\section{INTRODUCTION}

Sleep problems are increasingly becoming a public health concern. Globally, it is estimated
Strengths and limitations of this study

- This was a multicentre study with a large sample size; specifically, we recruited 3810 healthcare workers from 317 departments at 33 tertiary hospitals in the Heilongjiang Province, China, using multistage stratified random sampling.

- Considering the hierarchical structure of the study sample, a two-level logistic model was applied to examine determinants of sleep problems in order to obtain more accurate and reliable results.

- Although the results of the study may not be generalisable to healthcare workers in other countries, the findings likely accurately reflect the sleep problems of many Chinese healthcare workers, particularly those working in tertiary public hospitals in China.

- Information regarding the exposure and outcome was obtained via a self-report questionnaire which may have introduced report bias.

- The cross-sectional design limited our ability to establish causal relationships based on the results.

that $7.6 \%$ of the population has sleep problems. ${ }^{1}$ Common sleep problems include difficulty falling asleep, frequent night-time awakenings, parasomnias, noisy breathing, snoring and obstructive sleep apnoea. ${ }^{2}$ In China, workers in a variety of occupations are at risk of sleep problems, although sleep problems are particularly evident among healthcare workers. ${ }^{3}$ Many scholars have reported a high prevalence of sleep problems among Chinese healthcare workers, ranging from $21 \%$ to $65.5 \% .^{4-6}$ In fact, it has been shown that sleep problems are common among healthcare workers worldwide, including clinicians, nurses, medical technicians and administrative staff.

For example, in a study by Hayashino et $a l, 30.7 \%$ of Japanese healthcare workers reported having difficulty initiating sleep. ${ }^{7}$ Moreover, a study performed in Italy found that the prevalence of sleep disturbances 
among healthcare workers was extremely high, even among healthy controls in the study, with $24.6 \%$ of workers reporting difficulties falling asleep and $31.7 \%$ experiencing frequent awakenings during the night. ${ }^{8}$ In a study in Iran, nearly $43 \%$ of healthcare workers reported different degrees of sleep problems. ${ }^{9}$

Paying special attention to sleep problems among healthcare workers is essential for several reasons. First, sleep problems can affect the health and safety of these workers. For instance, various studies have confirmed that sleep problems have a powerful influence on the risk of cardiovascular disease, immune disorders and cancer. ${ }^{10-12}$ Sun and colleagues reported a significant negative correlation between anxiety and sleep problems in healthcare workers. ${ }^{4}$ Moreover, Kling et al reported that sleep problems are associated with an increased risk of work injury. ${ }^{13}$ Second, sleep problems affect both the health of the healthcare workers and patient safety and the quality of medical services the healthcare workers provide. Indeed, there is clear evidence indicating that sleep deprivation caused by long working hours can affect both the health of healthcare workers and the safety of patients. ${ }^{14}$ Further, sleep deprivation, long working hours and working during the night have been found to lead to medical errors, such as increases in the rates of surgical complications, needlestick injuries, adverse drug events and misdiagnosis. ${ }^{15-18}$

Currently, there is tremendous pressure on the healthcare system in China given the increasing size of the ageing population ${ }^{19}$ and the elevated incidence of chronic diseases such as cancer ${ }^{20}$ and cardiovascular diseases. ${ }^{21}$ In response to the increasing demands on healthcare services, the workloads and hours worked by healthcare workers have likewise increased, which may also lead to more frequent sleep problems in these individuals. One prior study with healthcare workers indicated that long working hours were the critical determinant of sleep health. ${ }^{22}$ However, few studies have focused on the relationship between working hours and sleep problems in healthcare workers in China. Moreover, Kim et $a l$ suggested that frequent night shifts are likely to be an important factor affecting sleep problems among healthcare workers. ${ }^{23}$

Furthermore, chronic pain, which is common among healthcare workers, ${ }^{24}$ has been shown to be related to sleep problems, ${ }^{25}$ although it remains unclear which specific site of chronic pain most greatly affects sleep problems. Health-related behaviours are also an important potential influencing factor. For example, research has shown that unhealthy diets are associated with sleep problems, while a healthy diet can effectively improve sleep quality. ${ }^{26} \mathrm{~A}$ recent study conducted in Japan observed that healthcare workers who reported having trouble initiating sleep consumed more alcohol and exercised less. ${ }^{7}$ In addition, it has been noted that sleep health assessment should be multidimensional, with sleep duration being one of the most important aspects. ${ }^{27} 28$ Although sleep needs differ among individuals due to genetic and environmental factors, ${ }^{29}$ shorter sleep duration may increase the likelihood of sleep problems. ${ }^{30}$

In 2009, China launched a nationwide systematic reform of healthcare services. Although the reform was successful in some areas, additional steps are required to reform the delivery of China's healthcare services. Particularly, primary healthcare facilities have not been able to perform a gate-keeping function, and most patients in China prefer to visit tertiary hospitals, especially tertiary public hospitals, even for common and minor illnesses. In 2016, there were approximately 3.27 billion patient visits to Chinese hospitals, $49.8 \%$ of which were visits to tertiary hospitals. ${ }^{31}$ A survey of the Chinese Medical Doctor Association in 2014 showed that $92 \%$ of healthcare workers in tertiary hospitals had to work overtime, and $72 \%$ of the healthcare workers who work $>60$ hours/week on average are employed in tertiary hospitals in China. ${ }^{32}$ Therefore, the sleep problems of healthcare workers in tertiary hospitals are of paramount importance. Nevertheless, population-based prevalence data on sleep problems among healthcare workers in tertiary hospitals in China are limited. Further, the relationships among sleep problems, work factors, health-related behaviours and chronic pain remain to be discovered in this population.

Therefore, the purposes of the present study were to investigate the prevalence of self-reported sleep problems among healthcare workers in tertiary public hospitals in China and to identify potential factors associated with sleep problems among these individuals. This study has several advantages. First, although it has been established that sleep problems are common among healthcare workers, relevant studies examining tertiary hospital employees in China are limited. Second, considering the hierarchical structure of the study sample, a two-level logistic model was applied to examine determinants of sleep problems in order to obtain more accurate and reliable results. Third, in contrast to previous reports, ${ }^{33-35}$ this was a multicentre study covering a large sample of healthcare workers in the Heilongjiang Province of China.

\section{METHODS}

\section{Data collection and study population}

This study took place in Heilongjiang Province, in Northeast China, where there were 689 public hospitals in 2014, of which 82 were tertiary public hospitals. ${ }^{36}$ The study included a representative sample of healthcare workers from tertiary hospitals, including clinicians (physicians, surgeons, paediatricians, gynaecologists, emergency doctors and so on), medical technicians (pharmacists, radiological technicians, laboratory physicians and so on) and office workers (administrative department personnel, finance personnel and so on), who were selected using a multistage cluster sampling method. First, 33 tertiary public hospitals were selected at random to serve as survey locations for this study and all selected hospitals participated (100\% response rate). Second, the departments of each hospital were coded, and several 
Table 1 Characteristics of questionnaire respondents and results of the univariate analysis

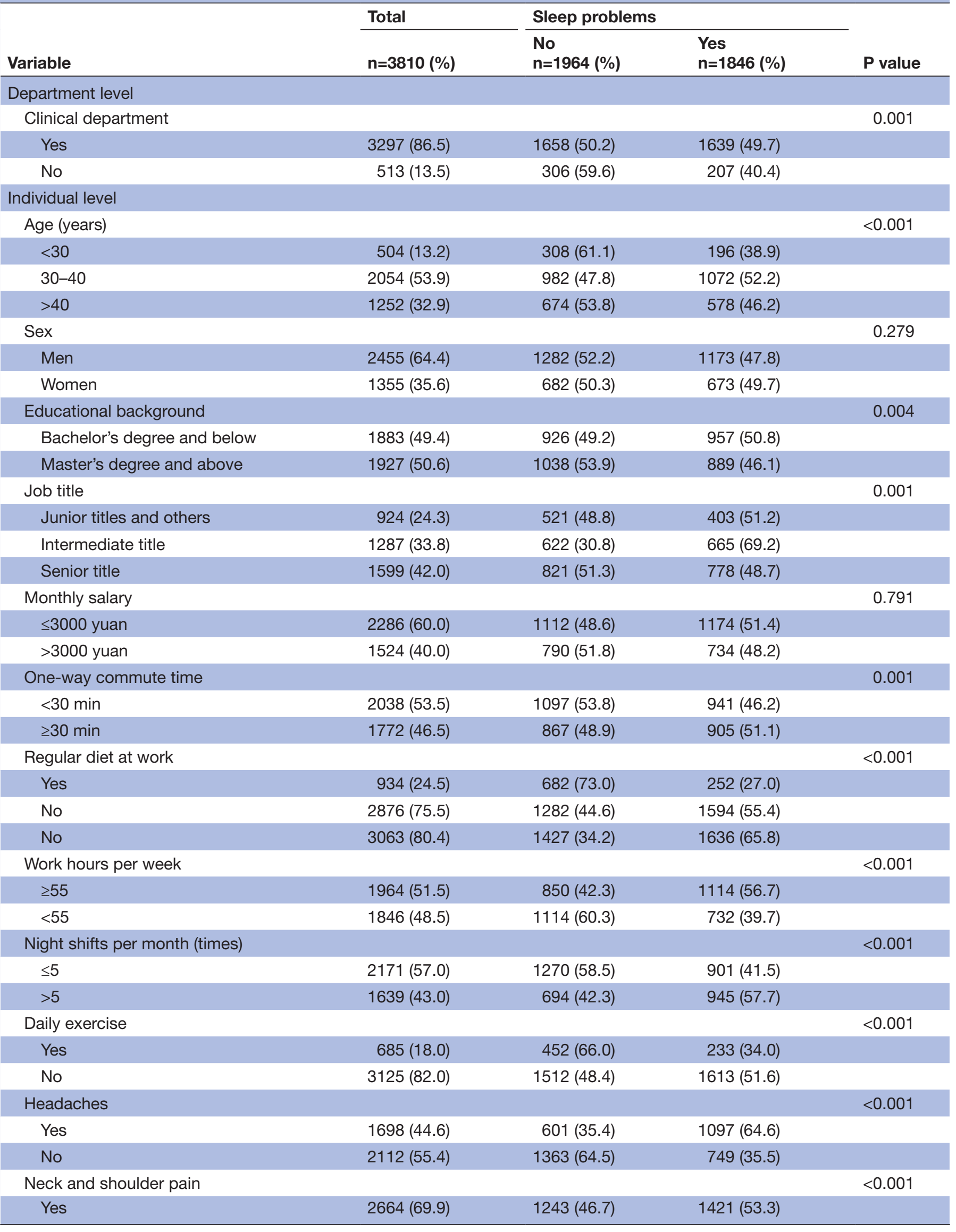


Table 1 Continued

\begin{tabular}{|c|c|c|c|c|}
\hline \multirow[b]{2}{*}{ Variable } & \multirow{2}{*}{$\begin{array}{l}\text { Total } \\
\mathrm{n}=3810(\%)\end{array}$} & \multicolumn{2}{|c|}{ Sleep problems } & \multirow[b]{2}{*}{$P$ value } \\
\hline & & $\begin{array}{l}\text { No } \\
n=1964(\%)\end{array}$ & $\begin{array}{l}\text { Yes } \\
n=1846(\%)\end{array}$ & \\
\hline No & $1146(30.1)$ & 721 (62.9) & $425(37.1)$ & \\
\hline Lumbar and back pain & & & & $<0.001$ \\
\hline Yes & $2441(64.1)$ & $1111(45.5)$ & $1330(54.5)$ & \\
\hline No & 1369 (35.9) & 853 (62.3) & $516(37.7)$ & \\
\hline Knee pain & & & & $<0.001$ \\
\hline Yes & 975 (25.6) & 340 (34.9) & $635(65.1)$ & \\
\hline No & 2835 (74.4) & 1624 (57.3) & $1211(42.7)$ & \\
\hline
\end{tabular}

departments were randomly selected from each hospital. The sample size at each level was based on the proportion of the number of workers in the hospital at that level. In the final sample, 4007 healthcare workers from 317 departments were invited to participate in the study. The healthcare workers in the selected departments completed a self-administered questionnaire (see online supplementary additional file 1 for details). After the data cleaning process, incomplete or anomalous data $(n=197)$ were excluded, leaving a final sample of 3810 participants (95\% response rate).

\section{Variables}

A structured questionnaire was designed to obtain data regarding demographics, sleep problems, working conditions, chronic pain and health-related behaviours.

\section{Outcome measure (dependent variable)}

The main outcome was the presence of sleep problems, which was a binary variable $(1=y e s ; 0=n o)$. The presence of sleep problems was assessed from each participant's self-report. Participants were asked the question 'Overall, in the last 30 days, how much of a problem did you have with sleeping, such as falling asleep, waking up frequently during the night or waking up too early in the morning?' with the following five response options: none, mild, moderate, severe and extreme. Participants who answered 'extreme' and 'severe' were considered to have sleep problems. This definition was adopted by previous studies that used the same survey question to assess sleep problems. $^{137}$

\section{Individual-level variables (independent variables)}

Individual-level variables included sociodemographic indicators (age, sex, educational background, job title and monthly salary), working conditions (average weekly working hours, number of night shifts per month and one-way commute time), health-related behaviours (physical exercise and regularity of diet) and experience of chronic pain (headache, neck and shoulder pain, lumbar and back pain and knee pain).

Age was categorised into three groups $(<30,30-40$ and $>40$ years) and job title was considered an ordinal categorical variable (junior title or no title, intermediate job title and senior title). The median monthly salary of participants in this study was 3000 yuan. Therefore, we coded monthly salary as $\leq 3000$ yuan $(=0)$ and $>3000$ yuan $(=1)$. Average weekly working hours were evaluated with the question: 'How much time do you work on average per week?' The median number of weekly working hours reported by participants in this study was 55 . Hence, the response categories were $1=\geq 55$ hours and $0=<55$ hours.

Herein, chronic pain was defined as any continuous or persistent intermittent pain experienced for a period longer than 3 months. ${ }^{38}$ We asked participants whether they had experienced chronic pain that had not improved in the past 30 days in the following regions: headache, neck and shoulder, lumbar and back and knee. The response categories were $1=y e s$ and $0=$ no. The coding of other individual-level variables is shown in online supplementary additional file 2 .

\section{Department-level variables (independent variable)}

The participants' department type was a level 2 explanatory variable in our analysis because individuals in the same department are not independent of each other. Among the healthcare workers in the study, some practitioners were from clinical departments (including internal medicine, surgery, gynaecology, paediatrics and so on) or laboratory, pathology, radiology or other technicians. Moreover, administrative-department personnel also participated in the survey. Therefore, this study was based on the functional attributes of the department, and whether the participants were from a clinical department ( $1=$ yes, $0=$ no) was an explanatory variable.

\section{Data analysis}

In this study, we used two statistical methods. The $\chi^{2}$ test was used to examine the independent associations between participant sleep problems and each independent variable. As the data were hierarchical, participants (level 1) were nested within departments (level 2) to create a two-level logistic model that was applied to assess associations between sleep problems and the study variables. 
Intraclass correlation coefficients (ICC) for healthcare workers were calculated to assess clustering by department. ${ }^{39}$ First, an empty model was constructed to verify whether our research model was applicable to the twolevel logistic model. A significant ICC would suggest that a multilevel logistic regression model is appropriate. Subsequently, in model 1, the department-level explanatory variable was added to the empty model. Next, in model 2, the individual-level explanatory variables were added to model 1. Meanwhile, we needed to judge whether the two multicategory variables (age and job title) should be introduced into the model as dummy or grouped linear variables according to the fit of the model. The likelihood ratio (LR) $\chi^{2}$ test can be used for model comparisons and the difference in $-2 \log$-likelihood between two models is used for the LR $\chi^{2}$ test. ${ }^{40}$ A statistically significant difference in $-2 \log$-likelihood between the two models indicated that the fit of the latter model was better. ${ }^{41}$ We also conducted subpopulation analyses to determine whether short sleep duration (Q15: 1=sleep duration $\leq 6$ hours, $0=$ sleep duration $>6$ hours ${ }^{42}$ significantly modified the observed associations. ${ }^{43}$

The two-level binary logistic regression models were estimated with the GLIMMIXED and NLMIXED procedures of SAS V.9.4 (SAS Institute). All other analyses were conducted with SPSS V.21.0 (IBM Corp), and p values $<0.05$ were considered to reflect statistical significance.

\section{Ethics approval}

The study received permission and assistance from each hospital to contact their healthcare workers. All participants were informed that the study was voluntary and confidential and that they had the right to discontinue their participation or withdraw their consent at any time without obligation to state their reasons. Interviews were conducted after the participants provided written informed consent. Survey data were collected using an anonymous questionnaire to protect the privacy of the participants (online supplementary additional file 3).

\section{Patient and public involvement}

No patients were involved.

\section{RESULTS \\ Participant characteristics}

The participants' general characteristics are shown in table 1. Overall, the participants were generally unable to maintain a regular diet $(75.5 \%)$. The most common types of chronic pain were neck and shoulder pain (69.9\%), and lumbar and back pain $(64.1 \%)$. Sleep problems were reported by $48.5 \%$ of participants. The univariate analysis indicated that demographics (excluding sex and monthly salary), chronic pain and working conditions were all related to participants' sleep problems $(\mathrm{p}<0.05)$.

\section{Self-reported sleep duration}

Most participants (46.7\%) reported a sleep duration of approximately 6 hours/ day regardless of department. Moreover, most of the $11.3 \%$ of respondents who reported sleeping less than 5 hours/day were working in clinical departments (figure 1).

\section{Multilevel analysis}

Table 2 presents the results from the multilevel analyses. The results of the empty model showed significant between-group variation (ICC $=0.1181, \mathrm{p}<0.001)$. An ICC of 0.1181 indicated that approximately $12 \%$ of the total variation in the outcome variables was caused by variation between the departments.

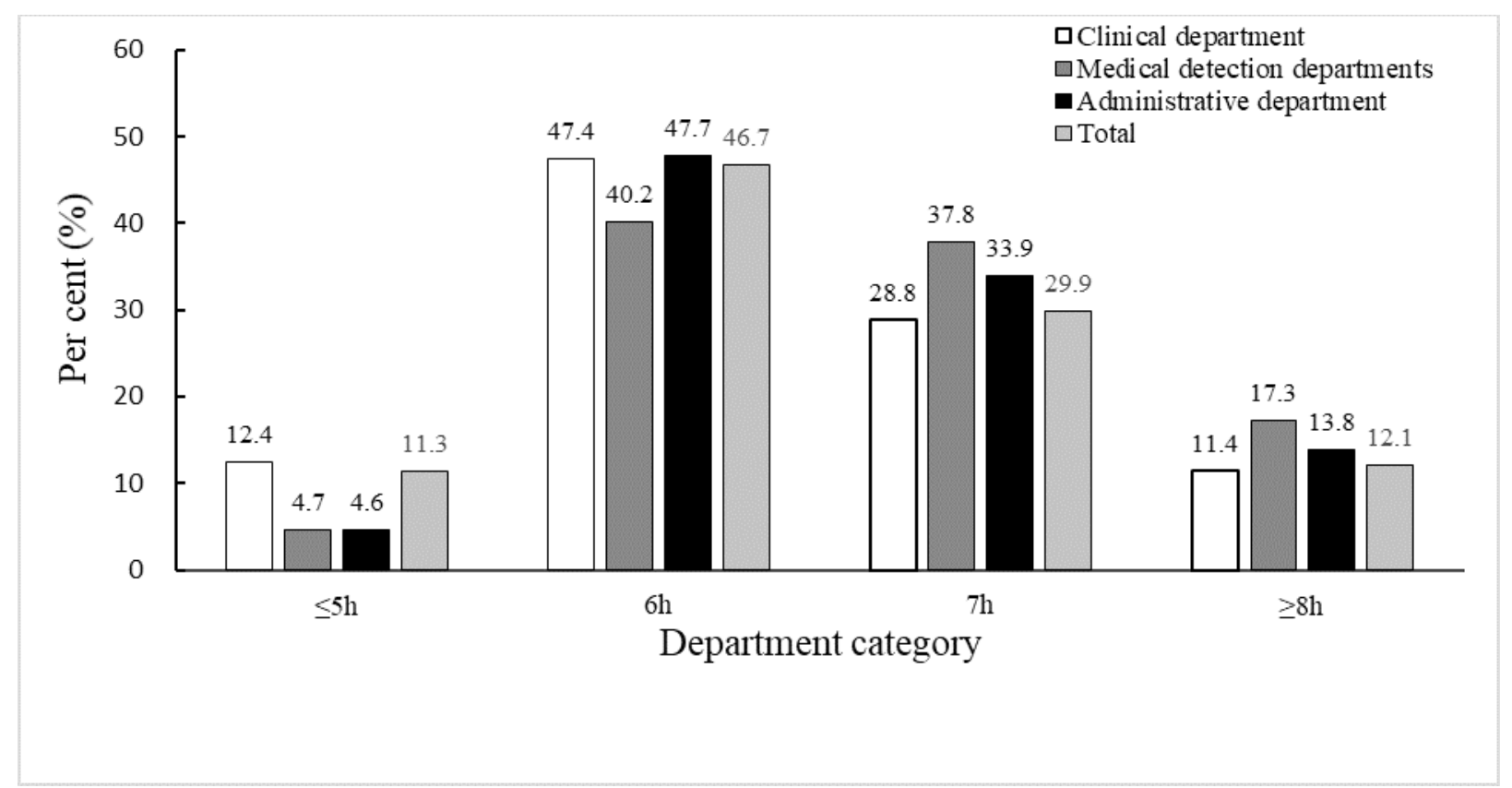

Figure 1 Subjective sleep duration (hours per night). 
Open access

Table 2 Factors related to sleep problems: results from the two-level logistic regression analysis $(n=3810)$

\begin{tabular}{|c|c|c|c|}
\hline Variable & Empty model & Model 1 & Model 2 \\
\hline \multicolumn{4}{|l|}{ Department level } \\
\hline \multicolumn{4}{|l|}{ Clinical department } \\
\hline Yes & & $1.53(1.15 \text { to } 2.04)^{\star}$ & $1.07(0.81$ to 1.40$)$ \\
\hline No & & 1 (reference) & 1 (reference) \\
\hline \multicolumn{4}{|l|}{ Individual level } \\
\hline \multicolumn{4}{|l|}{ Age (years) } \\
\hline$<30$ & & & 0.87 (0.63 to 1.20$)$ \\
\hline $30-40$ & & & $1.06(0.86$ to 1.31$)$ \\
\hline$>40$ & & & 1 (reference) \\
\hline \multicolumn{4}{|l|}{ Educational background } \\
\hline Bachelor degree and below & & & 0.87 (0.74 to 1.03$)$ \\
\hline Master's degree and above & & & 1 (reference) \\
\hline \multicolumn{4}{|l|}{ Job title } \\
\hline Junior title or no title & & & $0.71(0.55 \text { to } 0.92)^{*}$ \\
\hline Intermediate title & & & 0.87 (0.71 to 1.07$)$ \\
\hline Senior title & & & 1 (reference) \\
\hline \multicolumn{4}{|l|}{ One-way commute time } \\
\hline$<30 \min$ & & & 1.07 (0.92 to 1.24$)$ \\
\hline$\geq 30 \mathrm{~min}$ & & & 1 (reference) \\
\hline \multicolumn{4}{|l|}{ Regular diet at work } \\
\hline Yes & & & $0.44(0.36 \text { to } 0.53)^{\star *}$ \\
\hline No & & & 1 (reference) \\
\hline \multicolumn{4}{|l|}{ Daily exercise } \\
\hline Yes & & & $0.65(0.53 \text { to } 0.80)^{\star \star}$ \\
\hline No & & & 1 (reference) \\
\hline \multicolumn{4}{|l|}{ Work hours per week } \\
\hline$\geq 55$ & & & $1.41(1.20 \text { to } 1.66)^{\star \star}$ \\
\hline$<55$ & & & 1 (reference) \\
\hline \multicolumn{4}{|l|}{ Night shifts per month } \\
\hline$\leq 5$ & & & $1.43(1.21 \text { to } 1.69)^{\star *}$ \\
\hline$>5$ & & & 1 (reference) \\
\hline \multicolumn{4}{|l|}{ Headache } \\
\hline Yes & & & $2.64(2.27 \text { to } 3.07)^{\star \star}$ \\
\hline No & & & 1 (reference) \\
\hline \multicolumn{4}{|l|}{ Neck and shoulder pain } \\
\hline Yes & & & $1.29(1.09 \text { to } 1.52)^{\star}$ \\
\hline No & & & 1 (reference) \\
\hline \multicolumn{4}{|l|}{ Lumbar and back pain } \\
\hline Yes & & & $1.36(1.16 \text { to } 1.60)^{\star *}$ \\
\hline No & & & 1 (reference) \\
\hline \multicolumn{4}{|l|}{ Knee pain } \\
\hline Yes & & & $1.61(1.34 \text { to } 1.93)^{\star *}$ \\
\hline No & & & 1 (reference) \\
\hline Sigma $\mu$ (SE) & $0.4407(0.092)$ & $0.4061(0.088)$ & $0.2278(0.070)$ \\
\hline Intraclass correlation & $0.1181^{\star *}$ & $0.1099^{\star *}$ & $0.0648^{\star \star}$ \\
\hline -2 log-likelihood & 5159.4 & 5150.9 & 4538.0 \\
\hline
\end{tabular}

${ }^{*} \mathrm{P}<0.01 ;{ }^{* *} \mathrm{P}<0.001$. 
Subsequently, the department-level explanatory variable was introduced. The results showed that the odds of having sleep problems was approximately 1.5 times greater among healthcare workers in clinical departments than among those in non-clinical departments $(\mathrm{OR}=1.53,95 \%$ $\mathrm{CI}=1.15$ to 2.04$)$. After incorporating the departmentlevel explanatory variable, the -2 log-likelihood declined from 5159.4 to 5150.9 . The difference in -2 log-likelihood between model 1 and the empty model indicated that the fit of model 1 was better $(\mathrm{LR}=8.5, \mathrm{df}=1, \mathrm{p}<0.01)$.

In model 2, individual-level variables were added. The results showed that healthcare-worker sleep problems had an inverse association with regular diet $(\mathrm{OR}=0.44$, $95 \% \mathrm{CI}=0.36$ to 0.53$)$ and exercise $(\mathrm{OR}=0.65,95 \%$ $\mathrm{CI}=0.53$ to 0.80 ). The odds of having sleep problems were higher among participants with senior than with junior job titles $(\mathrm{OR}=0.71,95 \% \mathrm{CI}=0.55$ to 0.92$)$. Model 2 further suggested that chronic pain was positively associated with sleep problems. Specifically, participants with sleep problems were more likely to report having headaches $(\mathrm{OR}=2.64,95 \% \mathrm{CI}=2.27$ to 3.03). Furthermore, working hours $(\mathrm{OR}=1.41,95 \% \mathrm{CI}=1.20$ to 1.66$)$ and night shifts $(\mathrm{OR}=1.43,95 \% \mathrm{CI}=1.21$ to 1.69$)$ were associated with sleep problems. The difference in $-2 \log$-likelihood between model 2 and model 1 indicated that the fit of model 2 was better $(\mathrm{LR}=612, \mathrm{df}=14, \mathrm{p}<0.001)$. Meanwhile, department-level variables were also tested but showed no statistical significance.

Table 3 shows the results of the two-level logistic regression model for the subpopulation of healthcare workers with short sleep duration. In this subpopulation, the observed associations were mostly consistent with those identified with the two-level model comprising the total sample. However, in contrast to the analysis of the total sample, neck and shoulder pain $(\mathrm{p}=0.128)$ was not significantly associated with sleep problems in healthcare workers with short sleep durations.

\section{Factors related to headaches}

Table 4 shows factors related to headaches among respondents with sleep problems. We found that among the participants with headache, $62.4 \%$ worked $\geq 55$ hours/ week and $73.5 \%$ did not exercise daily.

\section{Discussion}

This study contributes to current knowledge on the extent of sleep problems among healthcare workers. We determined the prevalence of sleep problems experienced by the healthcare employees of tertiary public hospitals in the Heilongjiang Province, China and identified associated factors. In this study, more than $45 \%$ of the sample reported experiencing sleep problems, which is much higher than the prevalence reported for the general population of China $(36.2 \%){ }^{3}$

Herein, the factor most strongly associated with sleep problems among healthcare workers was headaches. We found that $44.6 \%$ of participants reported experiencing headaches for longer than 3 months, which had not improved in the past 30 days. Such findings are consistent with those of previous studies showing that headache is a very common symptom among healthcare workers. Sokolovic et al found that $61 \%$ of the healthcare workers they evaluated had experienced at least one type of headache in the previous 3 months. ${ }^{44}$ A cross-sectional study with healthcare workers conducted in Enugu, South East Nigeria showed that $12 \%$ of the participants had severe headaches that affected their sleep. ${ }^{45}$ From a clinical perspective, it has been suggested that the relationship between headaches and sleep problems may be bidirectional, ${ }^{46}$ whereby headache treatment is crucial for relieving sleep problems, while sleep improvement is also likely to reduce headache symptoms in healthcare workers. In addition, we analysed factors related to the participants' headaches and found that among respondents with sleep problems, irregular diet, working overtime, lack of exercise and neck and shoulder, lumbar and back and knee pain were associated with headaches. These findings highlight the importance of addressing these factors to reduce the high incidence of headaches among healthcare workers.

Our study additionally confirmed the negative effects of other types of chronic pain on sleep, suggesting that chronic pain in different parts of the body increases the likelihood of sleep problems. A study by Andersen et al with healthcare workers also indicated that chronic musculoskeletal pain in one body region increases the risk of developing chronic pain in other pain-free body regions. ${ }^{24}$ Therefore, when healthcare workers complain of chronic pain, they should be diagnosed and treated in a timely manner to reduce the risk of sleep problems and avoid the development of chronic pain in other body parts.

Our finding that night-shift work predicted a greater risk of sleep problems is consistent with the results of several previous studies. ${ }^{9} 34$ In hospitals, inpatient care usually requires round-the-clock services, which often translates to healthcare workers having to work extended shifts (especially night shifts) and long hours, which deprive them of sleep. Moreover, working during the night leads to misalignment between internal circadian rhythms and work-rest schedules, again resulting in fewer sleeping hours. ${ }^{47}$ As such, determining effective means to minimise the negative effects of shift work on health workers' sleep is essential. Previous studies have suggested that timed bright lights and light-blocking goggles can promote circadian adaptation to shift work. ${ }^{49}$ However, more reasonable night-shift working schedules may be a better solution to alleviate the sleep problems of healthcare employees; our data suggest that the number of night shifts per month should be reduced at a reasonable level. Additionally, and in line with the assertions of some previous studies, we suggest that it would be optimal to allow for time off of sufficient duration between shifts ${ }^{50}$ and to set a nap time to alleviate the high levels of sleepiness experienced while working during the night. ${ }^{5051}$ 
Table 3 Factors related to sleep problems: results from the two-level logistic regression analysis of healthcare workers with short sleep durations ( $\leq 6$ hours; $n=2210$ )

\section{Variable}

Department level

Clinical department

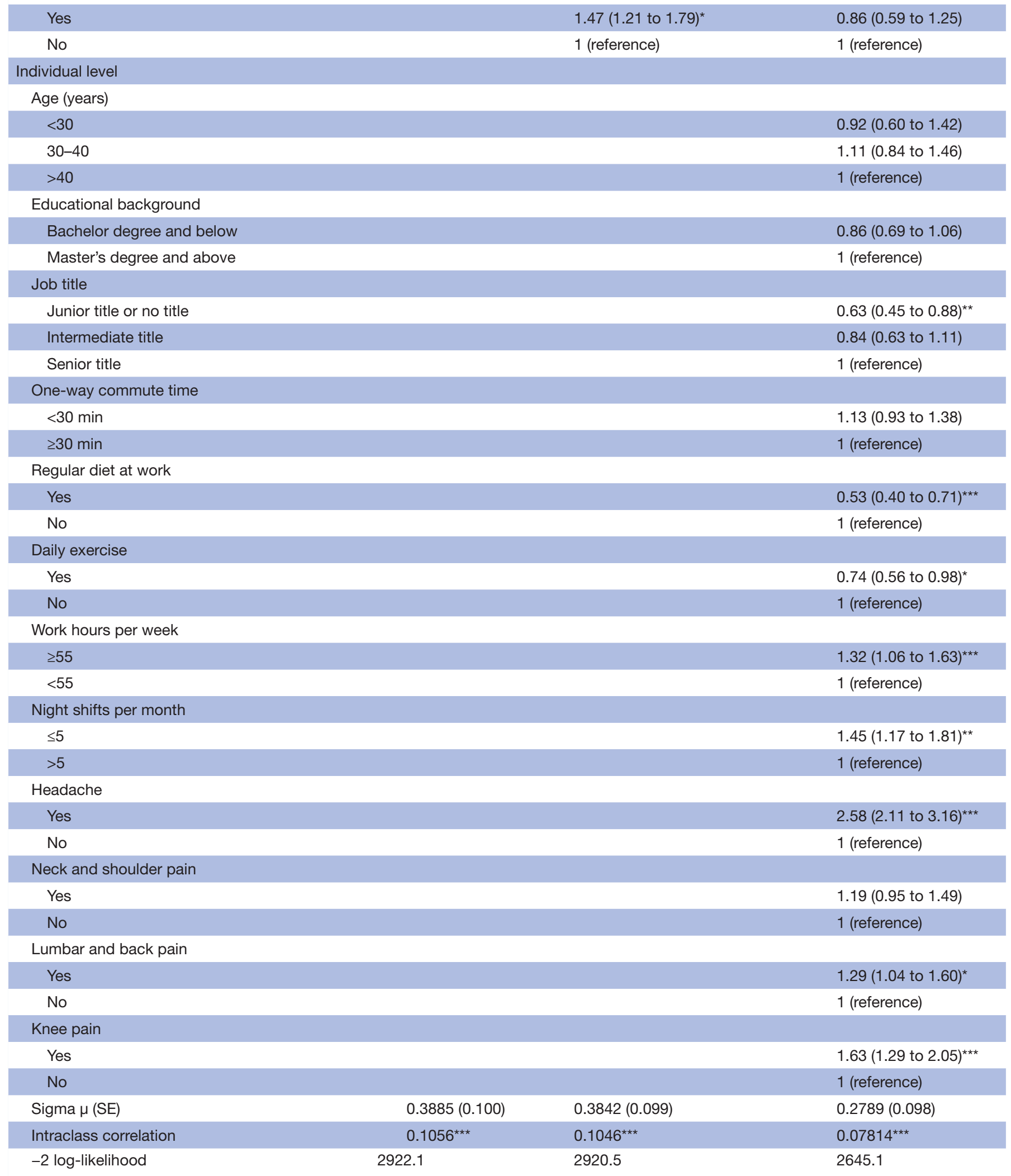

\section{Empty model}

Model 1

Model 2

1.11 (0.84 to 1.46$)$

1 (reference)

0.86 (0.69 to 1.06 )

$0.63(0.45 \text { to } 0.88)^{\star \star}$

0.63 to 1.11$)$

1.13 (0.93 to 1.38 )

1 (reference)

$0.53(0.40 \text { to } 0.71)^{\star \star \star}$

1 (reference)

0.74 (0.56 to 0.98 )

1 (reference)

$1.45(1.17 \text { to } 1.81)^{\star \star}$

1 (reference)

$58(2.11 \text { to } 3.16)^{\star}$

1.19 (0.95 to 1.49$)$

1 (reference)

$1.29(1.04$ to 1.60$)$

1 (reference)

0.2789 (0.098)

2645.1
$1.32(1.06 \text { to } 1.63)^{\star \star \star}$ 
Table 4 Factors related to headaches among respondents with sleep problems $(n=1846)$

\begin{tabular}{|c|c|c|c|}
\hline \multirow[b]{2}{*}{ Variable } & \multicolumn{2}{|l|}{ Headache } & \multirow[b]{2}{*}{$P$ value } \\
\hline & $\begin{array}{l}\text { Yes } n=1097 \\
(\%)\end{array}$ & $\begin{array}{l}\text { No } n=749 \\
(\%)\end{array}$ & \\
\hline Work hours per week & & & 0.015 \\
\hline$\geq 55$ & $685(62.4)$ & $429(57.3)$ & \\
\hline$<55$ & $412(37.6)$ & $320(42.7)$ & \\
\hline $\begin{array}{l}\text { Number of night } \\
\text { shifts per month }\end{array}$ & & & 0.173 \\
\hline 5 times or less & $525(47.9)$ & $376(50.2)$ & \\
\hline More than 5 times & $572(52.1)$ & $373(49.8)$ & \\
\hline $\begin{array}{l}\text { Do exercise every } \\
\text { day }\end{array}$ & & & $<0.001$ \\
\hline Yes & $120(10.9)$ & $113(15.1)$ & \\
\hline No & $977(89.1)$ & $636(84.9)$ & \\
\hline Regular diet at work & & & $<0.001$ \\
\hline Yes & $122(11.12)$ & $130(17.36)$ & \\
\hline No & 975 (88.88) & 619 (82.64) & \\
\hline $\begin{array}{l}\text { Neck and shoulder } \\
\text { pain }\end{array}$ & & & $<0.001$ \\
\hline Yes & $880(80.2)$ & $540(72.1)$ & \\
\hline No & $217(19.8)$ & $209(27.9)$ & \\
\hline $\begin{array}{l}\text { Lumbar and back } \\
\text { pain }\end{array}$ & & & $<0.001$ \\
\hline Yes & $833(75.9)$ & $496(66.2)$ & \\
\hline No & $264(24.1)$ & $253(33.8)$ & \\
\hline Knee pain & & & $<0.001$ \\
\hline Yes & $498(45.4)$ & $136(18.2)$ & \\
\hline No & $559(54.6)$ & $613(81.8)$ & \\
\hline
\end{tabular}

The present study also revealed that long working hours were a critical risk factor associated with sleep problems. A cross-sectional study in the USA reported that compensated working hours were consistently associated with sleep duration, such that as work duration increased, sleep duration decreased. ${ }^{52}$ In addition, the working hours of healthcare workers are evidently too long. According to the latest survey data collected in 2017, tertiary hospital employees in China work an average of 51.05 hours/ week, ${ }^{53}$ which is similar to the hours reported by our participants. Hale demonstrated that people working $>50$ hours/week were more likely to be short sleepers. ${ }^{54}$ Many countries have clear rules limiting the maximum working hours of healthcare workers. For example, in 2009, the European Union specified a maximum of 48 hours of work per week and established rest periods for healthcare workers. ${ }^{55}$ Although China's labour law specifies a maximum number of working hours, it does not apply to healthcare workers, and currently there are no established policies concerning the labour rights of healthcare workers. $^{56}$
Our findings confirmed that health-related behaviours play an important role in sleep problems. Indeed, our results showed that more than three-quarters of healthcare workers were unable to maintain a regular diet, and an irregular diet was significantly associated with sleep problems. Many healthcare workers do not have enough time to eat while working, and thus they order fast food from delivery services or simply delay their meals. However, research has revealed that short sleep duration is associated with higher caloric intake, mostly due to increased consumption of saturated fat. ${ }^{57}$ We recommend that healthcare workers should maintain a regular diet and increase the intake of micronutrients such as tryptophan and vitamin $\mathrm{B}$ to improve sleep problems. ${ }^{58}$ In addition, we also observed that participants who did not engage in regular exercise were more likely to experience sleep problems, which is consistent with the findings of previous research. ${ }^{59}$ A randomised controlled trial found that improved sleep quality was evident after an exercise intervention and that physical activity is beneficial in terms of quality and duration of sleep. ${ }^{58}$ For adults aged 18-64 years, the WHO recommends at least $150 \mathrm{~min}$ of moderate-intensity or at least 75 min of vigorous-intensity aerobic physical activity per week. ${ }^{60}$

A study funded by the Chinese Medical Doctor Association found 46 cases of karoshi, or 'death by overwork', among Chinese healthcare workers between 2013 and 2015, most of whom were aged 30-39 years. ${ }^{61}$ Although healthcare workers in China's top-three hospitals treat numerous patients, few workers are mindful of their own health issues. Studies have shown that continuous exposure to factors such as lack of sleep, exercise and a regular diet, as was found here, may increase the risk of chronic diseases among healthcare workers. ${ }^{106263}$ The fact that healthcare workers do not pay proper attention to their own health should be recognised by the government and society.

Overall, existing evidence indicates that it is important for healthcare workers to increase their sleep duration and reduce their workload. The effect that chronic pain, especially headache, has on healthcare worker sleep problems is of particular concern and requires attention. Furthermore, ensuring that workers engage in healthy behaviours is equally important. We make the following recommendations based on our findings: (1) hospitals should ensure that healthcare worker chronic pain in different body parts is diagnosed and treated in a timely manner; (2) healthcare workers should be aware of their own health issues and pay more attention to cultivating healthy behaviours, such as eating a regular diet and undergoing regular physical examinations; (3) more manageable working hours and night-shift work systems should be established and (4) health administrative departments should expand the scope of labour laws and formulate special regulations for the labour rights of healthcare workers.

Our study has some limitations of note. First, information regarding the exposure and outcome was obtained via a self-report questionnaire, which may have introduced report bias in these variables. In particular, we determined 
sleep problems via subjective evaluations of the participants. Future research should incorporate validated scales and clinical diagnoses to support the results obtained via self-reports. Second, all participants were from the Heilongjiang Province, China and thus the study findings may not be generalisable to other populations. Moreover, the sample did not include nursing staff, and hence the results cannot be used to characterise all healthcare workers. Third, as this was a cross-sectional study, we cannot establish causal relationships based on the results. Fourth, only one subpopulation of healthcare workers was examined to test for effect modification. Finally, survey weights were not considered in this study, and the results were based on an unweighted analysis, the OR of which might be smaller than that when considering weight. ${ }^{64}$ Therefore, sample weighting should be conducted in future analyses.

\section{Conclusions}

In summary, our findings suggest that nearly half of the healthcare workers in tertiary hospitals from the Heilongjiang Province in China have sleep problems. Chronic pain (headaches, knee pain, neck and shoulder pain and lumbar and back pain), long working hours and frequent night shifts were positively associated with sleep problems among healthcare workers. Of these, headaches were the most prominent risk factor for sleep problems in this population. However, a regular diet and daily exercise may reduce the likelihood of sleep problems. Most findings were not altered when analysing only participants with short sleep durations. These results indicate that to improve the sleep problems of healthcare workers, both medical institutions and health policy makers should work hand in hand to provide healthcare workers with reasonable work schedules, while the healthcare workers themselves should pay attention to their chronic pain problems and engage in regular diet and exercise.

Acknowledgements We are very grateful to Miaomiao Zhao, Ding Ding, Linghan Shan for providing the suggestion to draft the manuscript. We also thank all the participating organisations and participants.

Contributors HL conducted calculations, analysed results and drafted the manuscript. QW and $\mathrm{YH}$ were responsible for the overall design of the research, organised and conducted the survey. MJ, NN and LL designed the analyses framework. ZK and LG revised the paper. JJL, MC, XT and TZ assisted with the literature review and data collection. All authors approved the current version of this manuscript for publications.

Funding This research was supported by the Think Tank of Public Health Security and Health Reform of Heilongjiang Province and the CMB Distinguished Professorship Awards (Grant No. G16916400). This work was also supported by the National Natural Science Foundation of China (Grant No. 71333003).

Competing interests None declared.

Patient consent for publication Obtained.

Ethics approval The study protocol was reviewed and approved by the Research Ethics Committee of Harbin Medical University (project identification code: HMUIRB20170016) and the ethics committee from each hospital.

Provenance and peer review Not commissioned; externally peer reviewed.

Data availability statement № data are available.

Open access This is an open access article distributed in accordance with the Creative Commons Attribution Non Commercial (CC BY-NC 4.0) license, which permits others to distribute, remix, adapt, build upon this work non-commercially, and license their derivative works on different terms, provided the original work is properly cited, appropriate credit is given, any changes made indicated, and the use is non-commercial. See: http://creativecommons.org/licenses/by-nc/4.0/.

\section{ORCID iDs}

Huan Liu http://orcid.org/0000-0002-1882-1160

Mingli Jiao http://orcid.org/0000-0001-7405-5571

\section{REFERENCES}

1 Koyanagi A, Stickley A. The association between sleep problems and psychotic symptoms in the general population: a global perspective. Sleep 2015;38:1875-85.

2 Owens JA, Mindell JA. A clinical guide to pediatric sleep. Journal of the American Academy of Child \& Adolescent Psychiatry 2005;44:720-1.

3 Chinese Medical Association. China sleep quality index announced 2014, 2014

4 Sun W, Fu J, Chang Y, et al. Epidemiological study on risk factors for anxiety disorder among Chinese doctors. J Occup Health 2012;54:1-8.10.1539/joh.11-0169-OA

5 Tian H, Di Y, Song J. Investigation of sleep quality and influncing factors of medical workers in a grade -A tertiary hospitals. Chinese Journal of Social Medicine 2015;32:48-51.

6 Yang X, Wang R, Liu Z, et al. Relationship between sleep quality and mental health of physicians. China Journal of Health Psychology 2007;15:654-6.

7 Hayashino Y, Fukuhara S, Suzukamo Y, et al. Relation between sleep quality and quantity, quality of life, and risk of developing diabetes in healthy workers in Japan: the high-risk and population strategy for occupational health promotion (HIPOP-OHP) study. BMC Public Health 2007;7:129.

8 Sleep deprivation, sleep disorders, fatigue, stress and the risk of occupational injuries and errors among health-care workers: a multiapproach epidemiological study.

9 Ghalichi L, Pournik O MG. Sleep quality among health care workers. Arch Iran Med 2013;16:100-3.

10 Buxton OM, Marcelli E. Short and long sleep are positively associated with obesity, diabetes, hypertension, and cardiovascular disease among adults in the United States. Soc Sci Med 2010;71:1027-36.10.1016/j.socscimed.2010.05.041

11 Irwin MR. Why sleep is important for health: a psychoneuroimmunology perspective. Annu Rev Psychol 2015;66:143-72.10.1146/annurev-psych-010213-115205

12 Gottlieb DJ, Redline S, Nieto FJ, et al. Association of usual sleep duration with hypertension: the Sleep Heart Health Study. Sleep 2006;29:1009-14.10.1093/sleep/29.8.1009

13 Kling RN, McLeod CB, Koehoorn M. Sleep problems and workplace injuries in Canada. Sleep 2010;33:611-8.10.1093/sleep/33.5.611

14 Eddy R. Sleep deprivation among physicians. British Columbia Medical Journal 2005;4:176-80.

15 Ayas NT, Barger LK, Cade BE, et al. Extended work duration and the risk of self-reported percutaneous injuries in interns. JAMA 2006;296:1055-62.10.1001/jama.296.9.1055

16 Chaudhury PK, Warnock GL, Whalen TV, et al. CAGS and ACS evidence based reviews in surgery. Risks of complications by attending physicians after performing nighttime procedures. Can J Surg 2012;55:337-9.

17 Mycyk MB, McDaniel MR, Fotis MA, et al. Hospitalwide adverse drug events before and after limiting weekly work hours of medical residents to 80. Am J Health Syst Pharm 2005;62:1592-5.10.2146/ ajhp040527

18 Lockley SW, Landrigan CP, Barger LK, et al. When policy meets physiology: the challenge of reducing resident work hours. Clin Orthop Relat Res 2006;449:116-27.

19 Department of Economic and Social Affairs Population Division. World population ageing 2015. United Nations, 2015: 135-54.

20 Chen W, Zheng R, Baade PD, et al. Cancer statistics in China, 2015. CA: A Cancer Journal for Clinicians 2016;66:115-32.10.3322/ caac. 21338

21 Moran A, Gu D, Zhao D, et al. Future cardiovascular disease in China: Markov model and risk factor scenario projections from the coronary heart disease policy model-china. Circ Cardiovasc Qual Outcomes 2010;3:243-52.

22 Kobayashi T, Suzuki E, Takao S, et al. Long working hours and metabolic syndrome among Japanese men: a cross-sectional study. BMC Public Health 2012;12:395.10.1186/1471-2458-12-395

23 Kim M-S, Kim T, Lee D, et al. Mental disorders among workers in the healthcare industry: 2014 National health insurance data. Ann of Occup and Environ Med 2018;30.10.1186/s40557-018-0244-x 
24 Andersen LL, Clausen T, Carneiro IG, et al. Spreading of chronic pain between body regions: prospective cohort study among health care workers. EJP 2012;16:1437-43.10.1002/j.1532-2149.2012.00143.x

25 Jank R, Gallee A, Boeckle M, et al. Chronic pain and sleep disorders in primary care. Pain Res Treat 2017;2017:1-9.

26 St-Onge M-P, Mikic A, Pietrolungo CE. Effects of diet on sleep quality. Advances in Nutrition 2016;7:938-49.10.3945/an.116.012336

27 Buysse DJ. Sleep health: can we define it? does it matter? Sleep 2014;37:9-17.

28 Knutson KL, Phelan J, Paskow MJ, et al. The National Sleep Foundation's Sleep Health Index. Sleep Health 2017;3:234-40.10.1016/j.sleh.2017.05.011

29 Watson NF, Badr MS, Consensus Conference P,. et al. joint consensus statement of the American Academy of Sleep Medicine and Sleep Research Society on the recommended amount of sleep for a healthy adult: methodology and discussion. Sleep 2015;38:1161-83.

30 Seyedmehdi SM, Rahnama N, Yazdanparast T, et al. Prevalence of snoring and the risk of sleep apnea in hospital staff. Work 2016;55:765-72.10.3233/WOR-162460

31 National Bureau of statistics. China health statistical yearbook 2017. Beijing Union Medical University Press 2017;118.

32 Chinese Medical Doctor Association. Chinese doctors practicing white paper, 2015. Available: http://www.cmda.net/zlwqgzdt/596. jhtml [Accessed 14 Apr 2018].

33 Jafari Roodbandi A, Choobineh A, Daneshvar S. Relationship between circadian rhythm amplitude and stability with sleep quality and sleepiness among shift nurses and health care workers. International Journal of Occupational Safety and Ergonomics 2015;21:312-7.10.1080/10803548.2015.1081770

34 Alemohammad ZB, Taghavi SME, Sharifian A. Sleep quality and restless legs syndrome among health-care workers: shift workers and Non-shift workers. J Sleep Sci 2016;1:74-9.

35 Kolo ES, Ahmed AO, Hamisu A, et al. Sleep health of healthcare workers in Kano, Nigeria. Niger J Clin Pract 2017;20:479-83.

36 National Health and Family Planning Commission. China health statistical yearbook 2015. 11. Beijing: China Union Medical University Press, 2015.

37 Stranges S, Tigbe W, Gómez-Olivé FX, et al. Sleep problems: an emerging global epidemic? Findings from the indepth WHO-SAGE study among more than 40,000 older adults from 8 countries across Africa and Asia. Sleep 2012;35:1173-81.10.5665/ sleep.2012

38 Merskey H. International Association for the Study of Pain: classification of chronic pain. descriptions of chronic pain syndromes and definitions of pain terms. Pain 1986;3:S1-226.

39 Chen W, Zhou F, Hall BJ, et al. Is there a relationship between geographic distance and uptake of HIV testing services? A representative population-based study of Chinese adults in Guangzhou, China. PLoS One 2017;12:e0180801.

40 Wang J, Xie H, Fisher JH. Multilevel models: applications using SAS, 2009.

41 Huang J, Pan X-L, Li A. Multi-level modelling of the factors that influence the participation of disabled rural individuals in social medical insurance in China. BMC Health Serv Res 2013;13:58.

42 Ertel KA, Berkman LF, Buxton OM. Socioeconomic status, occupational characteristics, and sleep duration in African/ Caribbean immigrants and US white health care workers. Sleep 2011;34:509-18.10.1093/sleep/34.4.509

43 Burns RD. Energy balance-related factors associating with adolescent weight loss intent: evidence from the 2017 national youth risk behavior survey. BMC Public Health 2019;19:1206.10.1186/ s12889-019-7565-8
44 Sokolovic E, Riederer F, Szucs T, et al. Self-Reported headache among the employees of a Swiss university hospital: prevalence, disability, current treatment, and economic impact. $J$ Headache Pain 2013;14:29

45 Onwuekwe I, Onyeka T, Aguwa E, et al. Headache prevalence and its characterization amongst hospital workers in Enugu, South East Nigeria. Head Face Med 2014;10.10.1186/1746-160X-10-48

46 Holland PR. Headache and sleep: shared pathophysiological mechanisms. Cephalalgia 2014;34:725-44.10.1177/0333102414541687

47 Zhang Y, Punnett L, McEnany GP, et al. Contributing influences of work environment on sleep quantity and quality of nursing assistants in long-term care facilities: a cross-sectional study. Geriatr Nurs 2016;37:13-18.10.1016/j.gerinurse.2015.08.010

48 Burgess HJ, Sharkey KM, Eastman Cl. Bright light, dark and melatonin can promote circadian adaptation in night shift workers. Sleep Med Rev 2002;6:407-20.10.1053/smrv.2001.0215

49 Neil-Sztramko SE, Pahwa M, Demers PA, et al. Health-related interventions among night shift workers: a critical review of the literature. Scand J Work Environ Health 2014;40:543-56.10.5271/ sjweh.3445

$50 \mathrm{Li} \mathrm{J}$, Bidlingmaier M, Petru R, et al. Impact of shift work on the diurnal cortisol rhythm: a one-year longitudinal study in junior physicians. J Occup Med Toxicol 2018;13.10.1186/s12995-0180204-y

51 Rebecca SC, Howard SK, Mac DT, et al. Improving alertness and performance in emergency department physicians and nurses: the use of planned naps. Annals of Emergency Medicine 2006;48:596-604.

52 Basner M, Fomberstein KM, Razavi FM, et al. American time use survey: sleep time and its relationship to waking activities. Sleep 2007;30:1085-95.10.1093/sleep/30.9.1085

53 Chinese Medical Doctor Association. Chinese doctors practicing white paper, 2017. Available: http://www.cmda.net/u/cms/www/ 201807/06181247ffex.pdf [Accessed 20 May 2018].

54 Hale L. Who has time to sleep? J Public Health 2005;27:205-11.10.1093/pubmed/fdi004

55 Lancet T. Doctors' training and the European Working Time Directive. The Lancet 2010;375.10.1016/S0140-6736(10)60977-4

56 Ren Y. Study on labor rights guarantee of medical staff in China. Legal System and Society 2017;4:293-4.

57 Patel SR, Hu FB. Short sleep duration and weight gain: a systematic review. Obesity 2008;16:643-53.

58 Tan X, Saarinen A, Mikkola TM, et al. Effects of exercise and diet interventions on obesity-related sleep disorders in men: study protocol for a randomized controlled trial. Trials 2013;14:235-9.10.1186/1745-6215-14-235

59 Han Y, Yuan Y, Zhang L, et al. Sleep disorder status of nurses in general hospitals and its influencing factors. Psychiatria Danubina 2016;28:176-83.

60 World Health Organization. Global recommendations on physical activity for health, 2010.

61 Shan HP, Yang XH, Zhan XL, et al. Overwork is a silent killer of Chinese doctors: a review of Karoshi in China 2013-2015. Public Health 2017;147:98-100.

62 Thomas SJ, Calhoun D. Sleep, insomnia, and hypertension: current findings and future directions. J Am Soc Hypertens 2017;11:122-9.

$63 \mathrm{Yu} \mathrm{H}$, Xie L-F, Chen K, et al. Initiating characteristics of earlyonset type 2 diabetes mellitus in Chinese patients. Chin Med $J$ 2016;129:778-84.

64 Bethany AB JD. Alternatives for analysis of complex sample surveys: a comparison of SAS, SUDAAN and am software. SAS Global Forum 2007:2659-66. 